\title{
Opto-electronic Properties of Nano-electronic Materials
}

\author{
Bahare Agahi Keshe ${ }^{a}$, Ali Asghar Khakpoor ${ }^{\text {** }}$ \\ ${ }^{a}$ Young Researchers and Elite Club, West Tehran Branch, Islamic Azad University, Tehran, Iran \\ ${ }^{b}$ Department of Physics, Islamic Azad University-Central Tehran Branch, (IAUCTB), Tehran, Iran
}

Received: November 17, 2016; Revised: May 23, 2017; Accepted: June 20, 2017

\begin{abstract}
Nanoelectronic is nanotechnology applied in the context of electronic circuits and systems. Molecular electronic, which is supposed to replace silicon electronic in the future, is an incipient branch of Nanotechnology which focusing on the organic molecules. Since recognizing and examining this family of Nanostructures needs a long time and very expensive, an appropriate pattern to predict electronic properties is very beneficial; Topological Indices Method (TIM) is a useful approach for this purpose. This study is to present a simple model based on graph theory to predict electronic and optical properties of Circumacenes. Therefore, it is first tried to prove a theorem for RRR index in of Circumacenes family. Then RRR index is measured for some Circumacenes family members. Electronic and physical properties of Circumacenes family $\left(\mathrm{C}_{8(\mathrm{n}+2) / 3} \mathrm{H}_{(2 \mathrm{n}+22) / 3}\right)$ including Ionization Energy, Binding Energy, Gap Energy, and Electron Affinity Energy, were measured using Gaussian 09 Software by Hartree-Fock method. Finally, the relationships described electro-optical properties of Circumacenes family achieved by RRR index.
\end{abstract}

Keywords: Nanoelectronic, Circumacenes, Binding Energy, Gap Energy, Electron Affinity

\section{Introduction}

Nano-technology, among which Nano-electronic is one of the most used branches, is a meeting point for different sciences in the future. Nanoelectronic is nanotechnology applied in the context of electronic circuits and systems.

Today's knowledge requires increasing the capacity of data restoration, data transition, advancements in sensor manufacturing technologies and making electronic components as small as possible; the electronic components' being smaller not only increases the speed of the process, but also reduces the amount of consumed energy, two important goals which are accessible through Nano-electronic technique ${ }^{1-3}$. Today's electronic industry is based on silicon; this industry is 50 years old and has gradually matured technologically, industrially, and financially. Molecular electronic, which is supposed to replace silicon electronic in the future, is an incipient branch of Nanotechnology. Since minifying the size of electronic components on Nano-scale confronts various limitations, focusing on the molecular electronic is a considerable point which should attract attention. The molecular electronic is a branch of science based on Nanotechnology with multiple applications in electronic industry in which organic molecules are central. Aromatic hydrocarbon from the root of benzene can provide suitable environments for electron transition due to p orbitals, upper and lower electron clouds, and resonance phenomenon. Electronic circuits and logic gates are designed out of the joining of this hydrocarbons ${ }^{4-7}$.

* e-mail: ali.khakpoor@iauctb.ac.ir
Circumacenes is a family of organic molecules with the chemical formula of $\mathrm{C}_{(8 \mathrm{n}+16) / 3} \mathrm{H}_{(2 \mathrm{n}+22) / 3}$ which is focused in molecular electronic ${ }^{8,9}$. The size of Circumacenes is a few nanometers to several hundred nanometers, particularly for heavy circumacenes. Since recognizing and examining this family of Nanostructures needs huge time and money, an appropriate pattern to predict electronic features is very beneficial; Topological Indices Method (TIM), is a cheap and useful approach to gain this goal ${ }^{10-15}$. A single number, representing a chemical structure in graph-theoretical terms via the molecular graph, is called a topological descriptor and if it, in addition, correlates with a molecular property it is called topological index; it is used to understand physicochemical properties of chemical compounds. Topological indices are interesting since they capture some of the properties of a molecule in a single number. Hundreds of topological indices have been introduced and studied, starting with the seminal work by Wiener in which he used the sum of all shortest-path distances of a (molecular) graph for modeling physical properties of alkanes ${ }^{16}$.

\subsection{Hartree-Fock (HF) method}

The Gap Energy and Electron Affinity Energy were calculated by Gaussian 09 software and Hartree-Fock (HF) method. HF method is based on providing the wave function as a Slater determinant for N-body systems (N carbon atoms), which the basis are the wave functions of one carbon atom ${ }^{17,18}$. In this case, the interaction Hamiltonian of many-body systems as follows: 


$$
\widehat{H}=\sum_{i}^{N} \frac{P_{i}^{2}}{2 m_{i}}+\widehat{V}_{i}+V_{i j}
$$

Where $\frac{P_{i}^{2}}{2 m_{i}}, \widehat{V}_{i}$ and $V_{i j}$ are Kinetic energy, external interaction potential, and interaction of the electron - electron respectively. The external interaction potential is given by:

$$
\widehat{V}_{i}=-\sum_{k=1}^{N} \frac{Z_{k} e^{2}}{\left(r_{i}-R_{k}\right)}
$$

Where $r_{i}$ is the coordinates of the ith electrons and $Z_{k}$ is an atomic number of the nucleus which is in the coordinates of $\mathrm{R}_{\mathrm{k}}$. And the interaction of the electron - electron is given by:

$$
V_{i j}=\sum_{i<j}^{N} \frac{1}{\left(r_{i}-r_{j}\right)}
$$

\subsection{The RRR index}

Let $\mathrm{G}$ be a simple graph with $\mathrm{n}$ vertices and $\mathrm{m}$ edges, with vertex set $V(G)=\left\{v_{1}, v_{2}, \ldots, v_{n}\right\}$ and edge set $E(G)$. The edge connecting the vertices $v_{i}$ and $v_{j}$ will be denoted by $i$ and $j$. The degree of the vertex $v_{i}$ denoted by $d_{i}$ is the number of first neighbors of $v_{i}$ in the underlying graph. In chemical graphs, hydrogen is removed, or it is dehydrogenized, the vertices degree is maximum 4 and all the bonds are considered to be single ${ }^{19,20}$. RRR index (Reduced Reciprocal Randic) has been firstly defined by Ivan Gutman in 2014 as the following ${ }^{21}$ :

$$
R R R(G)=\sum_{i j \in E} \sqrt{\left(d_{i}-1\right)\left(d_{j}-1\right)}
$$

In which $d_{i}$ and $d_{j}$ are the degrees of vertices $i$ and $j$ which have common bonds.

\section{Research Method}

The purpose of this study is to present a simple model based on graph theory to predict electronic and optical properties of Circumacenes. Therefore, it is first tried to produce a relationship between the topological indices based on the number of rings; then RRR index values are measured for some members of Circumacenes family. Consider the simple graph of Circumacenes family $\left(\mathrm{C}_{(8 n+16) / 3} \mathrm{H}_{(2 n+22) / 3}\right)$ as presented in Scheme 1.

Theorem 1: Suppose $\mathrm{n}$ is the number of dual rings in Circumacenes family; therefore RRR index equals to:

$$
R R R(G)=\left(\frac{14+4 \sqrt{2}}{3}\right) n+\frac{8}{3}(\sqrt{2}-1)
$$

Proof: Consider a simple molecular graph which can be explicated from nine areas:

I. All vertices and edges that are located between two $\mathrm{L}_{1}$ and $\mathrm{L}_{2}$ levels and it is called $\mathrm{G}_{1}$.

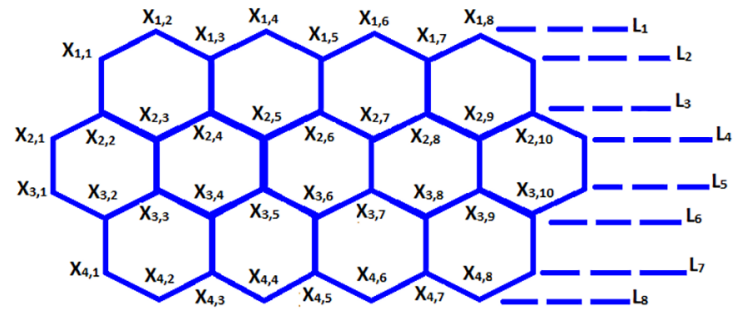

Scheme 1. Simple molecular graph of Circumacenes $\left(\mathrm{C}_{(8 \mathrm{n}+16) / 3} \mathrm{H}_{(2 \mathrm{n}+22) / 3}\right)$.

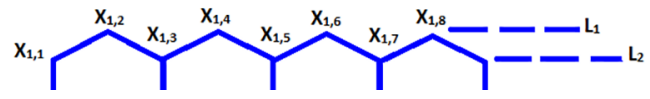

Scheme 2. All vertices and edges that are located between two $\mathrm{L}_{1}$ and $\mathrm{L}_{2}$ levels $\left(\mathrm{G}_{1}\right)$.

II. All vertices and edges that are located between two $\mathrm{L}_{2}$ and $\mathrm{L}_{3}$ levels and it is called $\mathrm{G}_{2}$.

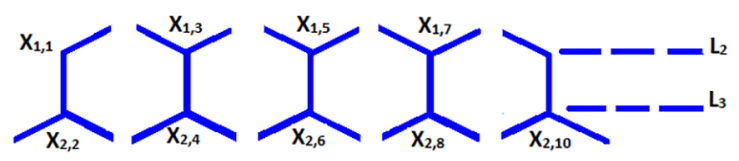

Scheme 3. All vertices and edges that are located between two $\mathrm{L}_{2}$ and $\mathrm{L}_{3}$ levels $\left(\mathrm{G}_{2}\right)$.

III. All vertices and edges that are located between two $\mathrm{L}_{3}$ and $\mathrm{L}_{4}$ levels and it is called $\mathrm{G}_{3}$.

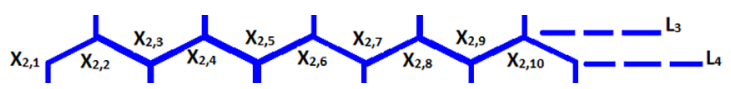

Scheme 4. All vertices and edges that are located between two $\mathrm{L}_{3}$ and $\mathrm{L}_{4}$ levels $\left(\mathrm{G}_{3}\right)$.

IV. All vertices and edges that are located between two $\mathrm{L}_{4}$ and $\mathrm{L}_{5}$ levels and it is called $\mathrm{G}_{4}$.

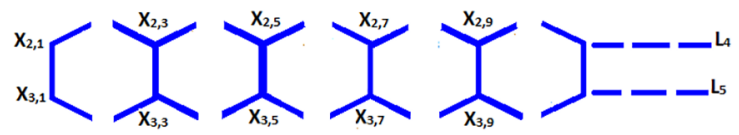

Scheme 5. All vertices and edges that are located between two $\mathrm{L}_{4}$ and $\mathrm{L}_{5}$ levels $\left(\mathrm{G}_{4}\right)$.

V. All vertices and edges that are located between two $\mathrm{L}_{5}$ and $\mathrm{L}_{6}$ levels and it is called $\mathrm{G}_{5}$.

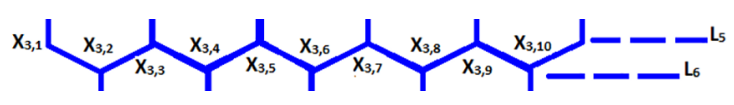

Scheme 6. All vertices and edges that are located between two $\mathrm{L}_{5}$ and $\mathrm{L}_{6}$ levels and it $\left(\mathrm{G}_{5}\right)$.

VI. All vertices and edges that are located between two $\mathrm{L}_{6}$ and $\mathrm{L}_{7}$ levels and it is called $\mathrm{G}_{6}$. 


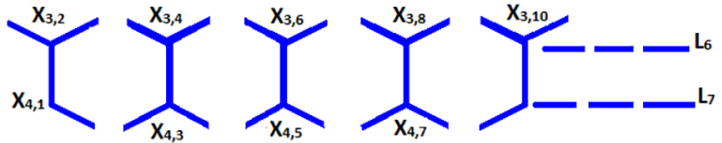

Scheme 7. All vertices and edges that are located between two $\mathrm{L}_{6}$ and $\mathrm{L}_{7}$ levels $\left(\mathrm{G}_{6}\right)$.

VII. All vertices and edges that are located between two $\mathrm{L}_{7}$ and $\mathrm{L}_{8}$ levels and it is called $\mathrm{G}_{7}$.

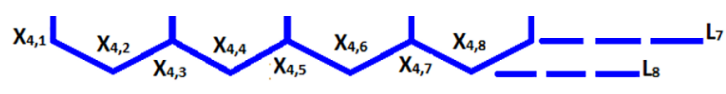

Scheme 8. All vertices and edges that are located between two $\mathrm{L}_{7}$ and $\mathrm{L}_{8}$ levels $\left(\mathrm{G}_{7}\right)$.

For $\mathrm{G}_{1}$, using Equation 4, we have:

$$
R R R\left(G_{1}\right)=\sum_{m=1}^{k-1} \sqrt{\left(d_{1, m}-1\right)\left(d_{1, m+1}-1\right)}
$$

The first and last terms are separated:

$$
\begin{aligned}
& \operatorname{RRR}\left(G_{1}\right)=\sqrt{\left(d_{1,1}-1\right)\left(d_{1,2}-1\right)}+ \\
& \sqrt{\left(d_{1, k-1}-1\right)\left(d_{1, k}-1\right)}+ \\
& \sum_{m=2}^{k-1} \sqrt{\left(d_{1, m}-1\right)\left(d_{1, m+1}-1\right)}
\end{aligned}
$$

And for the first two terms in Equation 7 we have

$$
\sqrt{\left(d_{1,1}-1\right)\left(d_{1,2}-1\right)}=\sqrt{\left(d_{1, k-1}-1\right)\left(d_{1, k}-1\right)}=1
$$

And for $\mathrm{m} \neq 1$ and $\mathrm{m} \neq \mathrm{k}$ we will have:

$$
\sqrt{\left(d_{1, m}-1\right)\left(d_{1, m+1}-1\right)}=\sqrt{2}
$$

And though Equations 8 and 9, we can conclude:

$$
\operatorname{RRR}\left(G_{1}\right)=1+1+\sum_{m=2}^{k-2} \sqrt{2}=2+\sqrt{2}(k-3)
$$

And since $k=(2 n+1) / 3$, therefore:

$$
\operatorname{RRR}\left(G_{1}\right)=2+\sqrt{2}\left(\frac{2 n-8}{3}\right)
$$

In $\mathrm{G}_{2}$, first we separate first and last terms:

$$
\begin{aligned}
& \operatorname{RRR}\left(G_{2}\right)=\sum_{m=1}^{k} \sqrt{\left(d_{1, m}-1\right)\left(d_{2, m}-1\right)}= \\
& \sqrt{\left(d_{1,1}-1\right)\left(d_{2,1}-1\right)}+\sqrt{\left(d_{1, k}-1\right)\left(d_{2, k}-1\right)}+ \\
& \sum_{m=2}^{k-1} \sqrt{\left(d_{1, m}-1\right)\left(d_{2, m}-1\right)}
\end{aligned}
$$

Equation 12 signifies for the first two terms as:

$$
\sqrt{\left(d_{1,1}-1\right)\left(d_{2,1}-1\right)}=\sqrt{\left(d_{1, k}-1\right)\left(d_{2, k}-1\right)}=\sqrt{2}
$$

And for two terms of $m \neq 1$ and $m \neq k$, we have:

$$
\sqrt{\left(d_{1, m}-1\right)\left(d_{2, m}-1\right)}=2
$$

Equations 13 and 14 will lead to:

$$
\operatorname{RRR}\left(G_{2}\right)=\sqrt{2}+\sqrt{2}+\sum_{m=2}^{k-1} 2=2 \sqrt{2}+(k-2) 2
$$

And since $\mathrm{k}=(\mathrm{n}+2) / 3$, so:

$$
\operatorname{RRR}\left(G_{2}\right)=2 \sqrt{2}+2\left(\frac{n-4}{3}\right)
$$

In $G_{3}$, first we separate first and last terms:

$$
\begin{aligned}
& \operatorname{RRR}\left(G_{3}\right)=\sum_{m=1}^{k-1} \sqrt{\left(d_{2, m}-1\right)\left(d_{2, m+1}-1\right)} \\
& \sqrt{\left(d_{2,1}-1\right)\left(d_{2,2}-1\right)}+\sqrt{\left(d_{2, k-1}-1\right)\left(d_{2, k}-1\right)}+ \\
& \sum_{m=2}^{k-12} \sqrt{\left(d_{2, m}-1\right)\left(d_{2, m+1}-1\right)}
\end{aligned}
$$

Equation 17 signifies for the first two terms as:

$$
\sqrt{\left(d_{2,1}-1\right)\left(d_{2,2}-1\right)}=\sqrt{\left(d_{2, k-1}-1\right)\left(d_{2, k}-1\right)}=\sqrt{2}
$$

And for two terms of $m \neq 1$ and $m \neq k$, we have:

$$
\sqrt{\left(d_{2, m}-1\right)\left(d_{2, m+1}-1\right)}=2(19)
$$

Equations 18 and 19 will lead to:

$$
R R R\left(G_{3}\right)=\sqrt{2}+\sqrt{2}+\sum_{m=2}^{k-2} 2=2 \sqrt{2}+(k-3) 2
$$

And since $\mathrm{k}=(2 \mathrm{n}+7) / 3$, so:

$$
\operatorname{RRR}\left(G_{3}\right)=2 \sqrt{2}+2\left(\frac{2 n-2}{3}\right)
$$

For $\mathrm{G}_{4}$, we can write:

$$
\operatorname{RRR}\left(G_{4}\right)=\sum_{m=1}^{k} \sqrt{\left(d_{2, m}-1\right)\left(d_{3, m}-1\right)}
$$

The first and last terms are separated:

$R R R\left(G_{4}\right)=\sqrt{\left(d_{2,1}-1\right)\left(d_{3,1}-1\right)}+\sqrt{\left(d_{2, k}-1\right)\left(d_{3, k}-1\right)}+$ $\sum_{m=1}^{k} \sqrt{\left(d_{2, m}-1\right)\left(d_{3, m}-1\right)}$

And for the first two terms in Equation 23 we have:

$$
\sqrt{\left(d_{2,1}-1\right)\left(d_{3,1}-1\right)}=\sqrt{\left(d_{2, k}-1\right)\left(d_{3, k}-1\right)}=1
$$

And for $\mathrm{m} \neq 1$ and $\mathrm{m} \neq \mathrm{k}$ we will have:

$$
\sqrt{\left(d_{2, m}-1\right)\left(d_{3, m}-1\right)}=2
$$


And though Equations 24 and 25, we can conclude:

$$
\operatorname{RRR}\left(G_{4}\right)=1+1+\sum_{m=2}^{k-1} 2=2+2(k-2)
$$

And since $\mathrm{k}=(\mathrm{n}+5) / 3$, therefore:

$$
\operatorname{RRR}\left(G_{4}\right)=2+2\left(\frac{n-1}{3}\right)
$$

The calculation procedure of $\mathrm{G}_{5}, \mathrm{G}_{6}$, and $\mathrm{G}_{7}$ areas are the same as $\mathrm{G}_{3}, \mathrm{G}_{2}$, and $\mathrm{G}_{1}$ respectively and is given through Equations 21, 16 and 11 Therefore,

$$
\begin{aligned}
& R R R(G)=R R R\left(G_{1}\right)+R R R\left(G_{2}\right)+ \\
& R R R\left(G_{3}\right)+R R R\left(G_{4}\right)+R R R\left(G_{5}\right)+ \\
& R R R\left(G_{6}\right)+\operatorname{RRR}\left(G_{7}\right)
\end{aligned}
$$

So, equation 5 is achieved and the theorem is proved.

Then RRR index is measured for some Circumacenes family members using equation 5 and the results are shown in Table 1.

\section{Results}

Electronic and physical properties of Circumacenes family $\left(\mathrm{C}_{8(\mathrm{n}+2) / 3} \mathrm{H}_{(2 \mathrm{n}+22) / 3}\right)$ including Ionization Energy, Binding Energy, Energy of Gap, and Electron Affinity Energy, were measured using Gaussian 09 Software and Hartree-Fock (HF) method. The results were compared to the experimental results and from the validated references ${ }^{22,23}$. These results were given in Table 2 .

Figures 1, 2, 3 and 4 respectively show Energy of Gap changes, Binding Energy, Electron Affinity Energy, and Ionization Energy for Circumacenes family according to RRR index as the results of this work $\left(1 \mathrm{eV}=1.6 \times 10^{-19} \mathrm{~J}\right)$.

As it is shown in figure 1, RRR index of Gap Energy changes for Circumacenes family was calculated with a high level of precision $\left(\mathrm{R}^{2}=0.9987\right)$. This prediction is possible using equation 29 .

$$
E_{g}=-2.312 \ln (R R R)+12.346
$$

Table 2. Electron Affinity Energy, Energy gap, Ionization Energy and Binding Energy of the first five members of Circumacenes family $\left(1 \mathrm{eV}=1.6 \times 10^{-19} \mathrm{~J}\right)$.

\begin{tabular}{lcccc}
\hline $\begin{array}{l}\text { Chemical } \\
\text { Formula }\end{array}$ & $\begin{array}{c}\mathrm{E}_{\text {affinity }} \\
(\mathrm{eV})\end{array}$ & $\begin{array}{c}\mathrm{E}_{\text {gap }} \\
(\mathrm{eV})\end{array}$ & $\begin{array}{c}\mathrm{E}_{\text {Ionization }} \\
(\mathrm{eV})\end{array}$ & $\begin{array}{c}\mathrm{E}_{\text {Bind }} \\
(\mathrm{eV})\end{array}$ \\
\hline $\mathrm{C}_{24} \mathrm{H}_{12}$ & 0.96 & 3.42 & 7.02 & 3.28 \\
$\mathrm{C}_{32} \mathrm{H}_{14}$ & 1.55 & 2.69 & 6.36 & 2.61 \\
$\mathrm{C}_{40} \mathrm{H}_{16}$ & 1.91 & 2.03 & 5.90 & 2.28 \\
$\mathrm{C}_{48} \mathrm{H}_{18}$ & 2.17 & 1.54 & 5.57 & 2.04 \\
$\mathrm{C}_{56} \mathrm{H}_{20}$ & 2.37 & 1.18 & 5.33 & 1.86 \\
\hline
\end{tabular}

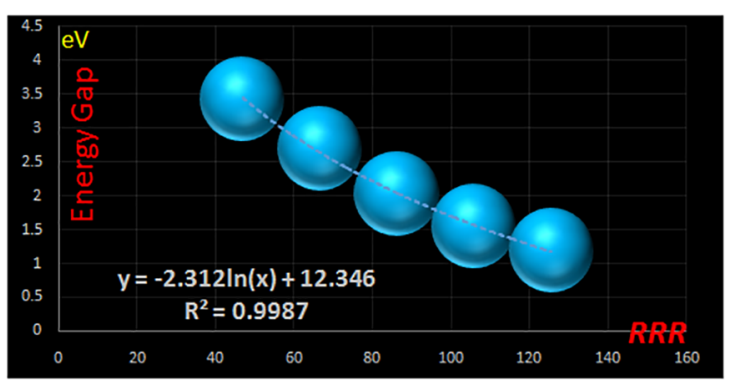

Figure 1. Energy Gap changes in Circumacenes family according to RRR index.

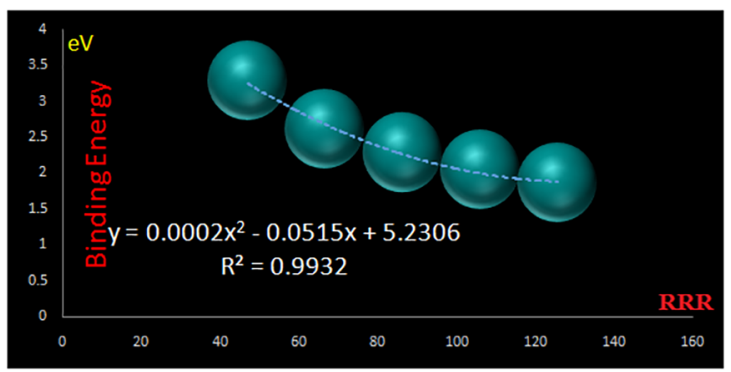

Figure 2. Binding Energy changes in Circumacenes family according to RRR index.

These predictions have been performed with a precision of $\mathrm{R}^{2}=0.9932$ for binding energy, $\mathrm{R}^{2}=0.9943$ for electron affinity energy and $\mathrm{R}^{2}=0.9993$ for ionization energy, using equations 30,31 and 32 .

\begin{tabular}{|c|c|c|c|}
\hline $\begin{array}{l}\text { Chemical } \\
\text { Formula }\end{array}$ & $\begin{array}{c}\text { IUPAC } \\
\text { Name }\end{array}$ & $\begin{array}{l}\text { Simple } \\
\text { Graph }\end{array}$ & $\begin{array}{l}\text { RRR } \\
\text { Index }\end{array}$ \\
\hline $\mathrm{C}_{24} \mathrm{H}_{12}$ & coronene & & 46.9705 \\
\hline $\mathrm{C}_{32} \mathrm{H}_{14}$ & ovalene & & 66.6274 \\
\hline $\mathrm{C}_{40} \mathrm{H}_{16}$ & circumanthracene & & 86.2842 \\
\hline $\mathrm{C}_{48} \mathrm{H}_{18}$ & circumtetracene & & 105.9411 \\
\hline $\mathrm{C}_{56} \mathrm{H}_{20}$ & circumpentacene & & 125.5979 \\
\hline
\end{tabular}

$$
\begin{gathered}
E_{\text {bind }}=0.0002(R R R)^{2}-0.515(R R R)+5.2306 \\
E_{\text {affinity }}=1.4305 \ln (R R R)-4.5027 \\
E_{\text {Ioniz }}=0.0002(R R R)^{2}-0.0522(R R R)+9.0628
\end{gathered}
$$

Table 1. RRR index for the first five members of Circumacenes family. 


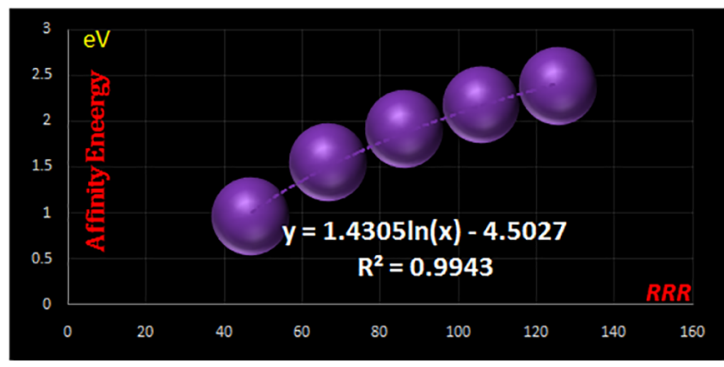

Figure 3. Electron Affinity Energy changes in Circumacenes family according to RRR index.

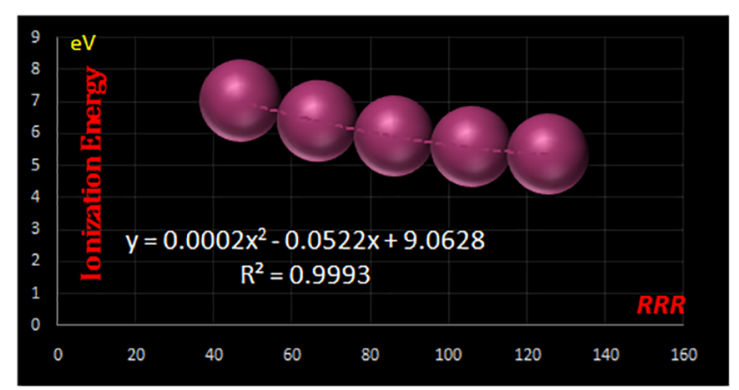

Figure 4. Shows Ionization Energy changes in Circumacenes family according to RRR index.

\section{Conclusion}

Table 3 shows the calculation results of Electron Affinity Energy, Energy Gap, Ionization Energy, and Binding Energy of Circumacenes family through TIM method. Table 3 shows the validity of TIM method in a comparison of results with the reference values (Table 3 ).

Table 3. Calculation Electron Affinity Energy, Energy Gap, Ionization Energy and Binding Energy of Circumacenes family through TIM method $\left(1 \mathrm{eV}=1.6 \times 10^{-19} \mathrm{~J}\right)$.

\begin{tabular}{lcccc}
\hline $\begin{array}{l}\text { Chemical } \\
\text { Formula }\end{array}$ & $\begin{array}{c}\mathrm{E}_{\text {affinity }} \\
(\mathrm{eV})\end{array}$ & $\begin{array}{c}\mathrm{E}_{\text {gap }} \\
(\mathrm{eV})\end{array}$ & $\begin{array}{c}\mathrm{E}_{\text {Ionization }} \\
(\mathrm{eV})\end{array}$ & $\begin{array}{c}\mathrm{E}_{\text {Bind }} \\
(\mathrm{eV})\end{array}$ \\
\hline $\mathrm{C}_{24} \mathrm{H}_{12}$ & 1.0040 & 3.4459 & 7.0521 & 3.2528 \\
$\mathrm{C}_{32} \mathrm{H}_{14}$ & 1.5041 & 2.6376 & 6.4726 & 2.6871 \\
$\mathrm{C}_{40} \mathrm{H}_{16}$ & 1.8739 & 2.0399 & 6.0477 & 2.2759 \\
$\mathrm{C}_{48} \mathrm{H}_{18}$ & 2.1675 & 1.5654 & 5.7773 & 2.0193 \\
$\mathrm{C}_{56} \mathrm{H}_{20}$ & 2.411 & 1.1719 & 5.6615 & 1.9172 \\
\hline
\end{tabular}

As it is shown, prediction of some physical and electrooptic properties of Circumacenes family with high precision is possible through TIM method and RRR index. The significance of this method is magnified in the case of heavier elements in article theoretical and experimental methods wasting much time and money still giving approximated results. Hereafter, some heavier members of Circumacenes family are exposed to TIM method. Equations 29 to 32 have been used to predict the Ionization Energy, Binding Energy, Gap Energy, and Electron Affinity Energy. The results are shown in Table 4.

When increasing the number of carbon atoms also increase the number of levels in conduction bond. Therefore the highest
Table 4. Predicting Electron Affinity Energy, Energy Gap, Ionization Energy and Binding Energy through TIM method $\left(1 \mathrm{eV}=1.6 \times 10^{-19} \mathrm{~J}\right)$.

\begin{tabular}{lccccc}
\hline $\begin{array}{l}\text { Chemical } \\
\text { Formula }\end{array}$ & $\begin{array}{c}\text { RRR } \\
\text { Index }\end{array}$ & $\begin{array}{c}\mathrm{E}_{\text {affinity }} \\
(\mathrm{eV})\end{array}$ & $\begin{array}{c}\mathrm{E}_{\text {gap }} \\
(\mathrm{eV})\end{array}$ & $\begin{array}{c}\mathrm{E}_{\text {Ionization }} \\
(\mathrm{eV})\end{array}$ & $\begin{array}{c}\mathrm{E}_{\text {Bind }} \\
(\mathrm{eV})\end{array}$ \\
\hline $\mathrm{C}_{64} \mathrm{H}_{22}$ & 145.2548 & 2.6190 & 0.8357 & 5.7002 & 1.9697 \\
$\mathrm{C}_{72} \mathrm{H}_{24}$ & 164.9116 & 2.8005 & 0.5422 & 5.8935 & 2.1768 \\
$\mathrm{C}_{80} \mathrm{H}_{26}$ & 184.5685 & 2.9616 & 0.2819 & 6.2414 & 2.5384 \\
$\mathrm{C}_{88} \mathrm{H}_{28}$ & 204.2253 & 3.1064 & 0.0479 & 6.7438 & 3.0545 \\
\hline
\end{tabular}

occupied molecular orbital (HOMO) is shifted to up and the lowest unoccupied molecular orbital (LUMO) is shifted to down the same time. On the other hand, by increasing the number of Rings increased electron cloud. With the increase in the electron cloud electron affinity energy is reduced.

\section{Acknowledgments}

We would like to thank Islamic Azad University Central Tehran Branch (IAUCTB) for helpful protections.

\section{References}

1. Yadav BC, Sikarwar S, Bhaduri A, Kumar P. Synthesis, Characterization and Development of Opto-Electronic Humidity Sensor using Copper Oxide Thin Film. IARJSET. 2015;2(11):105-109.

2. Sikarwar S, Yadav BC, Singh S, Dzhardimalieva GI, Pomogailo SI, Golubeva ND, et al. Fabrication of nanostructured yttria stabilized zirconia multilayered films and their optical humidity sensing capabilities based on transmission. Sensors and Actuators B: Chemical. 2016;232:283-291.

3. Sikarwar S, Yadav BC. Opto-electronic humidity sensor: A review. Sensors and Actuators A: Physical. 2015;233:54-70.

4. Waser R, ed. Nanoelectronics and Information Technology, $3^{\text {rd }}$ Ed. Weinheim: Wiley-VCH; 2012.

5. Patolsky F, Timko BP, Zheng G, Lieber CM. Nanowire-Based Nanoelectronic Devices in the Life Sciences. MRS Bulletin. 2007;32(2):142-149.

6. Pérez-Jiménez AJ, Sancho-García JC. Conductance Enhancement in Nanographene-Gold Junctions by Molecular $\pi$-Stacking. Journal of the American Chemical Society. 2009;131(41):1485714867.

7. Sancho-García JC, Pérez-Jiménez AJ. Charge-transport properties of prototype molecular materials for organic electronics based on graphene nanoribbons. Physical Chemistry Chemical Physics. 2009;11(15):2741-2746.

8. Jiang D, Dai S. Circumacenes versus periacenes: HOMO-LUMO gap and transition from nonmagnetic to magnetic ground state with size. Chemical Physics Letters. 2008;466(1-3):72-75.

9. Lias S. Ionization Energy Evaluation. In: Linstrom PJ, Mallard WG, eds. NIST Chemistry WebBook. Gaithersburg: National Institute of Standards and Technology; 2005.

10. Khakpoor AA. Prediction Electronic and Physical Properties of Nano Structures; Topological Index Method. International Journal of Advanced Research. 2015;3(6):1536-1540. 
11. Khakpoor AA, Agahi Keshe B. Electronic and Optical Properties of Nanostructures and Its Relationship with Harari Index. Journal of Materials Science and Chemical Engineering, 2015;3(8):1-5.

12. Khakpoor AA, Agahi Keshe B. Some Electronic and Optical Properties of Nanostructures Using the First Zagreb Index. International Journal of Advanced Research . 2015;3(5):548-551.

13. Khakpoor AA, Agahi Keshe B. Determination of physicalchemical properties of titanium organic compounds using topological indices; QSPR techniques. International Journal of Current Research. 2015;7(5):15686-15689.

14. Khakpoor AA, Agahi Keshe B. Physical and Electro-Optical Properties of Rylenes as Nanostructures Using Topological Indices Method. Journal of Nanoelectronics and Optoelectronics. 2016;11(3):280-283.

15. Khakpoor AA, Agahi Keshe B, Agahi Kesheh A. Nano Structures and Its Thermodynamic Properties Using TIM. Journal of Materials Science and Chemical Engineering. 2015;3(11):1-6.

16. Wiener H. Structural Determination of Paraffin Boiling Points. Journal of the American Chemical Society. 1947;69(1):17-20.
17. Sakurai JJ. Advanced Quantum Mechanics. Boston: AddisonWesley; 1967

18. Griffiths DJ. Introduction to Quantum Mechanics. $2^{\text {nd }}$ ed. Boston: Addison-Wesley; 2004.

19. Trinajstic N. Chemical Graph Theory. $2^{\text {nd }}$ ed. Boca Raton: CRC Press; 1992.

20. Ezra GS. Lecture Notes in Chemistry. Berlin Heidelberg: Springer-Verlag; 1982.

21. Gutman I, Furtula B, Elphick C. Three New/Old VertexDegree-Based Topological Indices. MATCH Communications in Mathematical and in Computer Chemistry. 2014;72(3):617-632.

22. Kadantsev ES, Stott MJ, Rubio A. Electronic structure and excitations in oligoacenes from ab initio calculations. The Journal of Chemical Physics. 2006;124(13):134901.

23. Malloci G, Mulas G, Cappellini G, Joblin C. Time-dependent density functional study of the electronic spectra of oligoacenes in the charge states $-1,0,+1$, and +2 . Chemical Physics. 2007;340(1-3):43-58. 